\title{
Minireview
}

\section{Cancer risks among BRCAI and BRCA2 mutation carriers}

\author{
E Levy-Lahad*,I and E Friedman ${ }^{2}$ \\ IInstitute of Medical Genetics, Shaare Zedek Medical Center, Hebrew University Medical School, Jerusalem, 91031 , Israel; ${ }^{2}$ Oncogenetics Unit, Chaim \\ Sheba Medical Center, Tel-Hashomer 53621; Sackler Faculty of Medicine, Tel Aviv University, Tel Aviv, 69978, Israel
}

BRCAI and BRCA2 mutations increase breast and ovarian cancer risks substantially enough to warrant risk reduction surgery, despite variable risk estimates. Underlying this variability are methodological issues, and also complex genetic and nongenetic effects. Although many modifying factors are unidentified, known factors can already be incorporated in individualised risk prediction. British Journal of Cancer (2007) 96, II - I5. doi:I0.I038/sj.bjc.6603535 www.bjcancer.com (c) 2007 Cancer Research UK

Keywords: BRCAI; BRCA2; penetrance; breast cancer; ovarian cancer

BRCA1 and BRCA2 were identified as genes mutated in hereditary breast/ovarian cancer by genetic analysis in families with multiple cases of these malignancies. In the following decade, as BRCA1 and BRCA2 testing became more common in patients with a personal or family history of cancer, numerous studies assessed cancer risks in carriers of these mutations. These studies have resulted in variable risk estimates, leading to difficulties in defining risk figures that are clinically applicable to the individual patient. However, they illuminated the complexities that underlie risk prediction even in the context of a single gene with major effects on cancer predisposition. The emerging picture is that breast and ovarian cancer risks in BRCA1 and BRCA2 carriers are substantially higher than in the general population, but that they are considerably affected by nongenetic, environmental factors, and by additional genetic modifiers.

\section{BREAST AND OVARIAN CANCER RISK IN WOMEN}

Original estimates of breast and ovarian cancer risks in carriers were based on the families used for positional cloning of the BRCA1 and BRCA2 genes, where all carriers had molecular testing, and all cancer diagnoses were validated. These families were chosen because they harboured multiple, early-onset cases, that is, they were essentially selected for high cancer risk. In the Breast Cancer Linkage Consortium (BCLC) families, by age 70 years, BRCA1 carriers had a breast cancer risk of $71 \%$ (95\% CI $53-82 \%)$ and an ovarian cancer risk of $47-63 \%$ (Easton et al, 1995). BRCA2 carriers had a breast cancer risk of $84 \%$ (95\% CI $43-95 \%)$, and an ovarian cancer risk of $27 \%$ (95\% CI, 0-47\%) (Ford et al, 1998). Many subsequent studies were case-based, that is, risk was estimated by analysis of family history in relatives of breast or ovarian cancer patients, often from hospital-based series (Antoniou et al, 2003). The design of these studies partially addressed the ascertainment bias inherent in studying highly selected, multiple-case families, but risk estimates were based on family history, rather than on testing carriers directly and validating their

*Correspondence: Professor E Levy-Lahad; E-mail: lahad@szmc.org.il Received 2 October 2006; revised 16 November 2006; accepted 17 November 2006 cancer status. With this design, misclassification can result from discrepancies between modelled $v s$ true carrier status, and from errors in cancer reporting by relatives, a particularly common problem for ovarian cancer. In a meta-analysis of such case-based studies, by age 70 years, in BRCA1 carriers breast cancer risk was $65 \%(95 \%$ CI $51-75 \%)$ and ovarian cancer risk was 39\% (95\% CI $22-51 \%)$, and in BRCA2 carriers breast cancer risk was $45 \%(95 \%$ CI $33-54 \%$ ) and ovarian cancer risk was $11 \%$ (95\% CI $4.1-18 \%$ ) (Antoniou et al, 2003). One study, performed in American Ashkenazi Jews (AJ), combined ascertainment of unselected breast cancer cases with direct genetic testing and clinical status validation in relatives (King et al, 2003). By age 70 years, for BRCA1 carriers, breast cancer risk was 69\% (SE 5\%) and ovarian cancer risk was $46 \%$ (SE 6\%), and for BRCA2 carriers, breast cancer risk was $74 \%$ (SE $8 \%$ ) and ovarian cancer risk was $12 \%$ (7\%). These risks continue to rise at older ages, reaching $\sim 80 \%$ for breast cancer at age 80 years (Easton et al, 1995; Ford et al, 1998; King et al, 2003). Thus, point estimates of risk are somewhat lower in case-ascertained, rather than family-ascertained studies, but because of the large confidence intervals, substantial overlap exists and many differences are not statistically significant. However, if 'true' risk estimates are those for any carrier in the population, even case-ascertained studies may be biased, because the very occurrence of cancer in a carrier suggests that other breast/ovarian cancer risk factors will be over-represented in her relatives, leading to overestimation of risk in carriers (Begg, 2002). These biases can be fully addressed only by population-based studies, which currently are technically feasible only in ethnic groups with founder mutations, for example, AJ and Iceland, where a few, easily tested mutations account for practically all deleterious changes in BRCA1 and BRCA2. A study of 5318 AJ volunteers identified 120 carriers (93 cancer free), and estimated cancer risk by comparing their family history with that of noncarriers (Struewing et al, 1997). Cancer risks were similar in BRCA1 and BRCA2 carriers, and by age 70 years breast cancer risk was $56 \%(95 \%$ CI $40-73 \%)$, and ovarian cancer risk was $16 \%(95 \%$ CI 6-28\%). While breast cancer risk is in range of other estimates, ovarian cancer risk is substantially lower, perhaps because of unverified family history. Also, cancer rates in non-carriers were relatively high in this study, which may have led to deflated risk estimates based on comparing carriers to non-carriers. Discussing 
all published studies of breast and ovarian cancer risk in BRCA1 and BRCA2 carriers is beyond the scope of this review, but we would like to address the variability of risk estimates in the literature. Some of the variation is clearly methodological: familybased studies are prone to ascertainment bias, and almost all caseand population-based studies performed so far could be prone to misclassification of genetic and clinical status. However, some of the variation is likely due to true biological causes, including effects of specific mutations (allelic effects), other genetic factors, and nongenetic, environmental influences. The assumption is that in sufficiently large studies these variations would be equally distributed and risk estimates would remain comparable, but sample sizes are not large in all studies, and some risk-affecting factors can differ significantly, especially when studies are performed in specific ethnic groups or in different countries.

\section{EFFECTS OF SPECIFIC MUTATIONS}

BRCA1 and BRCA2 are large genes, with thousands of different mutations. A clear genotype-phenotype correlation exists for BRCA2 mutations, where the central part of the gene (nt 30356629 in exon 11) is named the ovarian cancer cluster region (OCCR) because mutations within it are associated with an increased ovarian : breast cancer ratio. Compared to other BRCA2 mutations, OCCR mutations are associated with higher ovarian cancer risk $(\mathrm{RR}=1.88 ; 95 \% \mathrm{CI} 1.08-3.33)$ and lower breast cancer risk $(\mathrm{RR}=0.63 ; 95 \%$ CI 0.46-0.84) (Thompson and Easton, 2001). Similar studies on BRCA1 mutations are less conclusive, but suggest that mutations in the central part of the gene (nt $2401-$ $4190)$ are associated with lower breast cancer risk $(R R=0.71 ; 95 \%$ CI $0.58-0.86$ ), and that mutations in the $3^{\prime}$ end (beyond nt 4191 ) could be associated with lower ovarian cancer risk $(\mathrm{RR}=0.81 ; 95 \%$ CI 0.66-1.00) (Thompson and Easton, 2002). Most studies have not taken these general genotype-phenotype correlations into account. Furthermore, specific mutations could have unique risk profiles, and their relative prevalence in different studies could affect final risk estimates. In this context, one should note the locations of the common AJ and Icelandic mutations, which constitute a substantial fraction of carriers in many studies. In BRCA 1 , the common Jewish 185delAG and 5382insC mutations are outside the low breast cancer risk central region, and 5382insC is within the low ovarian cancer risk region. In BRCA2, the common Jewish mutation, 6174delT, is within the OCCR, whereas the common Icelandic mutation, 999del5, is outside the OCCR.

\section{OTHER GENETIC FACTORS - GENETIC MODIFIERS}

The phenotypic expression of inherited disease can vary widely even between individuals with the same disease-causing mutations, as a result of both nongenetic variation and polymorphisms/ mutations in other genes, known as genetic modifiers. There is epidemiological evidence for the existence of such modifiers for BRCA1 and BRCA2 mutations, since there is familial clustering of the cancer site: carriers in families with ovarian cancer index cases are at higher risk for ovarian cancer and at lower risk for breast cancer than carriers from families with breast cancer index cases (Easton et al, 1995; Antoniou et al, 2003; Simchoni et al, 2006). In the case of multiple generation families with different environments, familial clustering is likely to represent sharing of genetic modifiers within families. The search for genetic modifiers was originally limited to candidate genes, especially genes related to hormone metabolism and pathways involving BRCA1 and BRCA2. Length of repeat variations in the androgen receptor gene and in the steroid nuclear receptor coactivator AIB1/NCOA3 were reported to affect breast cancer risk (reviewed in Narod, 2002a), but this has not been confirmed (Spurdle et al, 2005, 2006). A noncoding polymorphism in RAD51, which binds BRCA2 in the
DNA repair process, has been shown to increase breast cancer risk in BRCA2 carriers $(\mathrm{HR}=3.2-5.5)$ in three independent studies, all performed in AJs (discussed in Simchoni et al, 2006). There has been one report of an HRAS-linked polymorphism affecting ovarian cancer risk in BRCA1 carriers, but no follow-up studies were published (Narod, 2002a). Thus, the only confirmed genetic modifier is RAD51 in AJ BRCA2 carriers. Whole genome analysis strategies are now being applied and may yield significant genetic modifiers. Because genetic modifiers are yet to be identified, they have not been accounted for in current risk-estimate studies.

\section{NON-GENETIC EFFECTS}

There are very significant nongenetic effects on breast and ovarian cancer risk in BRCA1 and BRCA2 carriers. This is evidenced by the consistent observation of increasing breast and ovarian cancer risks in carriers born in more recent years (Antoniou et al, 2003; King et al, 2003), although they carry the same mutations (and genetic modifiers). For example, an RR of 7.7 (95\% CI 2.6-23) for breast cancer risk was found in BRCA1 carriers born from 1960 on, compared to those born before 1920 (Antoniou et al, 2003). Further environmental influences are suggested by the effect of country of origin on cancer risk (Antoniou et al, 2003). Investigation of specific nongenetic factors has focused on factors known to affect risk for sporadic breast and ovarian cancer, for example, reproductive behaviour, hormonal exposure, and lifestyle habits (Narod, 2002a; Dumitrescu and Cotarla, 2005). Risk reduction surgeries (salpingo-oophorectomy and mastectomy) are commonly offered to carriers, and result in substantial, nongenetic decrease in breast/ovarian cancer risk. They are not discussed here, since most studies censor carriers at the time of first preventive surgery.

\section{Reproductive factors}

Age at menarche Younger age at menarche is associated with increased risk for sporadic breast cancer. An effect was not observed in BRCA2 carriers, but BRCA1 carriers whose age at menarche was $14-15$ years had a $54 \%$ reduction in breast cancer risk compared to those with menarche at $\leqslant 11$ years of age $(\mathrm{OR}=0.46,95 \%$ CI $0.30-0.69)$ (Kotsopoulos et al, 2005).

Pregnancy Increased parity is protective for sporadic breast cancer beyond age 40 years, but may increase risk for early-onset breast cancer. In BRCA1 and BRCA 2 carriers, parity effects may also be age dependent. While an early report suggested that parity may increase risk for early onset $(<40$ years) breast cancer in BRCA1 carriers (Narod, 2002a), a larger retrospective study of 1260 carrier pairs by the same group did not confirm this finding, and even observed decreased breast cancer risk in BRCA1 carriers with $\geqslant$ four children $(\mathrm{OR}=0.62,95 \%$ CI $0.41-0.94$, vs nulliparous carriers) (Cullinane et al, 2005). In BRCA2 carriers, this study found that parity caused a borderline increase in risk for breast cancer before age 50 years $(\mathrm{OR}=1.17$ for each pregnancy, $95 \% \mathrm{CI}$ $1.01-1.36$ ) (Cullinane et al, 2005). In a case-only study, young age at first pregnancy delayed onset of breast cancer in carriers (King et al, 2003), and a retrospective study of 1601 carriers found that in women over 40 years of age, each full-term pregnancy reduced breast cancer risk by $14 \%$ (95\% CI 6-22\%). An age effect was seen in that BRCA2 carriers with later first pregnancies had increased risk, whereas BRCA1 carriers with first birth over age 30 years were at lower risk than those with first birth before age 20 years (Andrieu et al, 2006a). Overall, the effect of parity on breast cancer in carriers is similar to that in sporadic cases.

Breast feeding In a case-control study of 965 BRCA1 and 280 BRCA2 pairs, breast feeding did not influence breast cancer risk in BRCA2 carriers, but BRCA1 carriers who breast fed for over 1 year 
were less likely to have had breast cancer than those who never breast fed $(\mathrm{OR}=0.55,95 \%$ CI $0.38-0.80)$ (Jernstrom et al, 2004). The retrospective cohort study of 1601 carriers did not show any breast feeding effect ( $\mathrm{HR}=0.89,95 \% \mathrm{CI} 0.62-1.27$ ) (Andrieu et al, 2006a).

Hormonal exposures - oral contraceptives (OC) The effect of OC on breast cancer risk in carriers is difficult to assess because of changing patterns of use and $\mathrm{OC}$ formulations with time. In a retrospective case-control study of 981 BRCA1 and 330 BRCA2 carrier pairs, there was no effect of $\mathrm{OC}$ on breast cancer risk in BRCA2 carriers, but in BRCA1 carriers risk for early-onset $(<40$ years) breast cancer was increased in women who first used OC before 1975 (OR $=1.42$, 95\% CI 1.17-1.75), who used OC before age 30 years $(\mathrm{OR}=1.29,95 \% \mathrm{CI} 1.09-1.52)$, or who used them for 5 or more years $(\mathrm{OR}=1.33,95 \%$ CI $1.11-1.60)$ (Narod et al, $2002 b)$. Two recent studies based on early-onset breast cancer cases, including small numbers $(<100)$ of carriers, found no general increase in breast cancer risk with OC use. One study found increased breast cancer risk only with teenage ( $<20$ years) OC use $(\mathrm{OR}=1.53(95 \%$ CI $1.17-1.99)$ per year of use at age $<20$ years) (Jernstrom et al, 2005), and in the others there was even a suggestion of decreased breast cancer risk within BRCA1 carriers $(\mathrm{OR}=0.22,95 \%$ CI $0.1-0.49$ for OC use of at least 1 year) (Milne et al, 2005). Altogether, these studies suggest that for breast cancer risk, OC have similar relative effects in carriers and non-carriers. These effects may be attenuated in newer, low-dose preparations, but the absolute effect may be higher in carriers. OC use is known to decrease ovarian cancer risk in the general population, and similar effects have been seen in most studies of carriers (Narod, 2002a). In a case-control study, ovarian cancer risk was reduced by $15 \%(\mathrm{OR}=0.85,95 \% \mathrm{CI} 0.53-1.36)$ with at least 1 year of OC use, and by $38 \%$ with 6 years or more of OC use (OR $=0.62,95 \%$ CI 0.35-1.09) (Whittemore et al, 2004).

Physical activity and body weight Most of the evidence suggests that in women at average risk, physical activity, and lack of obesity are protective against breast cancer. In a study of 48 unaffected carriers and 89 carriers with breast cancer, physical activity was not protective (Nkondjock et al, 2006), but caloric intake in the highest $v s$ the lowest tertile increased breast cancer risk (OR 2.76, $95 \%$ CI 1.10-7.02). A larger case-only study found that increased physical activity and lack of obesity in adolescence were associated with significantly delayed breast cancer onset in BRCA1 and BRCA2 carriers (King et al, 2003).

Radiation exposure Early radiation exposure increases breast cancer risk, raising the concern that early screening mammography in carriers may be harmful. In a case-control study of 3200 carriers, previous mammography did not increase breast cancer risk (OR 1.03, 95\% CI 0.85-1.25) (Narod et al, 2006). In contrast, a retrospective cohort study of 1601 carriers found that any exposure to chest X-rays was associated with an increased breast cancer risk $(\mathrm{HR}=1.54 ; P=0.007)$. Risk was increased in carriers aged 40 years and younger $(\mathrm{HR}=1.97 ; P<0.001)$, particularly those exposed only before the age of 20 years $(\mathrm{HR}=4.64$; $P<0.001$ ) (Andrieu et al, 2006b). Further studies may determine if these results imply differential effects of dose and developmental timing of radiation exposure.

While fewer factors seem to significantly influence BRCA2compared to BRCA1-related risks, this could be the result of smaller sample sizes of BRCA2 carriers and subsequent lack of power. The demonstration of multiple nongenetic effects on cancer risk in carriers requires controlling for these factors in risk assessment. Year of birth is now commonly included in risk models, but is unlikely to account for all environmental effects.

\section{MALE-SPECIFIC CANCER RISKS - MALE BREAST AND} PROSTATE CANCER

Data on male-specific cancer risks are much more limited than on female-specific cancer risks.

Male breast cancer $(M B C)$ is a major characteristic of the BRCA2-associated cancer syndrome. Cumulative risk for this malignancy was assessed in 164 BRCA2-BCLC families, which included 59 cases of male breast cancer, and risk was estimated at $2.8 \%$ (95\% CI $0.6-13.0 \%$ ) by age 70 years, rising to $6.9 \%$ by age 80 years (95\% CI $1.2-38.6 \%)$ (Thompson and Easton 2001). This corresponds to a RR of $\sim 80$-fold. Mutation location (within or outside the OCCR) does not influence MBC risk (Thompson and Easton, 2001). While BRCA1 carriers are at lower risk than BRCA2 carriers, they seem to be at increased risk compared to the general population. Cumulative MBC risk in BRCAl carriers has been estimated at $5.8 \%$ (95\% CI $1.3-10.4 \%)$ over the entire lifetime (to age $>80$ years), a figure based on four cases among 102 male carriers in a clinic-based study (Brose et al, 2002). In studies of MBC cases, the rate of BRCA1 mutations has been $3.2-10.4 \%$ (reviewed by Liede et al, 2004) significantly higher than the background rate.

Prostate cancer risk is also higher in BRCA2 compared to BRCA1 carriers. Cumulative prostate cancer risk assessed in 173 BCLC-BRCA2 families was $7.5 \%$ (95\% CI $5.7-9.3 \%)$ by age 70 years, corresponding to a RR of 4.65 (95\% CI 3.48-6.22), which may include a detection bias. A Dutch study of BRCA2 carriers reached similar conclusions, with a cumulative risk of 5.2\% $(95 \%$ CI 1.7-8.7\%) by age 70 years, reflecting an RR of 2.5 (95\% CI 1.63.8) (van Asperen et al, 2005). BCLC family-based studies found that prostate cancer risk in BRCA2 carriers depend on age and BRCA2 mutation location. Relative prostate cancer risk was higher in men younger than 65 years $(\mathrm{RR}=7.3(95 \% \mathrm{CI} 4.7-11.5)$ than in older men (RR 3.4 (85\% CI 2.3-4.9) (The BCLC, 1999), and mutations outside the OCCR were associated with higher risks (33.6\% (95\% CI $25.1-44.1 \%)$ by age 80 years) than mutations within the OCCR (19.2\% (95\% CI $10.7-33.1 \%$ ) by age 80 years) (Thompson and Easton, 2001). The lower risk in OCCR mutations $(\mathrm{OR}=0.52,95 \%$ CI $0.24-1.00)$ may explain why prostate cancer risk has not been consistently elevated in studies of BRCA2 in AJ (Liede et al, 2004). It is less clear whether BRCA1 mutations increase prostate cancer risk. In the BCLC-BRCA1 families, there was some evidence of an increased risk of prostate cancer for men younger than 65 years (RR 1.82, 95\% CI 1.01-3.29), but not for those aged 65 years or older $(\mathrm{RR}=0.84,95 \%$ CI $0.53-1.33)$ (Thompson and Easton, 2002). Studies in AJ have yielded conflicting results, but in general BRCA1 mutations have a limited contribution to prostate cancer risk in this population (Liede et al, 2004).

\section{RISK FOR OTHER CANCERS}

In addition to breast and ovarian cancer in women, and breast and prostate cancer in men, BRCA1 and BRCA2 carriers may be at higher risk for additional malignancies. However, the absolute risks for specific cancers at other sites are small (Gruber and Petersen, 2002; Thompson and Easton, 2002). Risk for malignancies at other sites has so far been addressed using two designs: family-based studies, which compare the observed $v s$ expected number of cases of a specific malignancy, and studies which compare rates of BRCA1/BRCA2 mutations in unselected cases of a specific malignancy with mutation rates in controls or in the general population. In family-based studies, diagnoses other than breast or ovarian cancer were confirmed by pathology or clinical records in only about half of the cases (The BCLC, 1999, Thompson and Easton, 2002; van Asperen et al, 2005), whereas in studies of mutation rates in specific cancers, all cases are confirmed by pathology records. This is an important issue when 
risk estimates are based on a small number of specific cancer cases. Thus, reports of possible excess risk of other gynaecological cancers (e.g. cervix and uterus), and gall bladder and bile duct cancer may represent misclassifications of ovarian and pancreatic cancer, respectively, and liver and bone cancers may represent distant metastases from other sites.

Colon and rectal cancer risk was originally thought to be higher in BRCA1, but not BRCA2 carriers (The BCLC, 1999; Thompson and Easton, 2002). However, in the largest family-based study, combined colorectal cancer risk was not increased (Gruber and Petersen, 2002) and a large study of 225 unselected AJ colon cancer cases did not find increased rates of BRCA1 or BRCA2 mutations (Niell et al, 2004). Malignant melanoma, both cutaneous and ocular, has been reported in BRCA2 families, and an excess risk has been reported in the BRCA2-BCLC families (The BCLC, 1999). This has not been confirmed in a smaller Dutch study (van Asperen et al, 2005), and studies of unselected uveal melanoma cases have not shown excess rates of BRCA2 mutations (Hearle et al, 2003). Taken together, this suggests that melanoma risk may be elevated in specific BRCA2 families, but not for all BRCA2 carriers.

Pancreatic cancer is currently the only additional malignancy for which there is unequivocal evidence for increased risk in BRCA1 and BRCA 2 carriers, although the absolute risk is small. In BRCA1 carriers pancreatic cancer risk carriers by age 70 years has been estimated to be $1.16 \%$ (95\% CI $0.83-1.61 \%$ ) in men, and $1.26 \%$ (95\% CI $0.92-1.72 \%)$ in women, reflecting a two-fold RR (Thompson and Easton, 2002). In BRCA2 carriers, the largest study is that of the BCLC which included data on 566 malignancies other than breast or ovarian cancers. This study estimated pancreatic cancer risk in BRCA2 carriers by age 70 years to be $2.1 \%(95 \%$ CI $1.2-3.0 \%)$ in men, and $1.5 \%$ (95\% CI $0.9-2.1 \%)$ in women, reflecting a combined RR of 3.51 (95\% CI 1.87-6.58) (The BCLC, 1999). A smaller Dutch study, based on 199 malignancies other than breast or ovarian cancer, estimated pancreatic cancer risk in BRCA2 carriers by age 70 years at $4.1 \%$ (95\% CI $1.0-7.3 \%)$ in men and $1.4 \%(95 \%$ CI $0-3.4 \%)$ in women (Van Asperen et al, 2005). These risk estimates are also consistent with the $4-7 \%$ rate of BRCA1 and BRCA2 mutations among unselected pancreatic cases (reviewed in Liede et al, 2004).

\section{CONCLUSION}

Breast and ovarian cancer risk in BRCA1 and BRCA2 carriers is a complex trait, affected by genetic modifiers and nongenetic factors. While further studies are necessary to define and quantify risk-factor effects, even now the best approach for the individual patient is perhaps a personalised one, which takes into account family history, ascertainment, and known environmental risk factors.

\section{ACKNOWLEDGEMENTS}

Work in ELL's laboratory was supported by the Breast Cancer Research Foundation. ELL and EF were supported by the Israel Cancer Association as part of the Israel Breast Cancer Genetics Consortium. We thank Ms Hadassa Hartman for her help in preparing this manuscript.

\section{REFERENCES}

Andrieu N, Easton DF, Chang-Claude J, Rookus MA, Brohet R, Cardis E, Antoniou AC, Wagner T, Simard J, Evans G, Peock S, Fricker JP, Nogues C, Van't Veer L, Van Leeuwen FE, Goldgar DE (2006b) Effect of chest $\mathrm{X}$-rays on the risk of breast cancer among BRCA1 and BRCA2 mutation carriers in the international BRCA1 and BRCA2 carrier cohort study: a report from the EMBRACE, GENEPSO, GEO-HEBON, and IBCCS Collaborators' Group. J Clin Oncol 24: $3361-3366$

Andrieu N, Goldgar DE, Easton DF, Rookus M, Brohet R, Antoniou AC, Peock S, Evans G, Eccles D, Douglas F, Nogues C, Gauthier-Villars M, Chompret A, Van Leeuwen FE, Kluijt I, Benitez J, Arver B, Olah E, Chang-Claude J (2006a) Pregnancies, breast-feeding, and breast cancer risk in the International BRCA1 and BRCA2 Carrier Cohort Study (IBCCS). J Natl Cancer Inst 98: 535-544

Antoniou A, Pharoah PD, Narod S, Risch HA, Eyfjord JE, Hopper JL, Loman N, Olsson H, Johannsson O, Borg A, Pasini B, Radice P, Manoukian S, Eccles DM, Tang N, Olah E, Anton-Culver H, Warner E, Lubinski J, Gronwald J, Gorski B, Tulinius H, Thorlacius S, Eerola H, Nevanlinna H, Syrjakoski K, Kallioniemi OP, Thompson D, Evans C, Peto J, Lalloo F, Evans DG, Easton DF (2003) Average risks of breast and ovarian cancer associated with BRCA1 or BRCA2 mutations detected in case series unselected for family history: a combined analysis of 22 studies. Am J Hum Genet 72: 1117-1130

Begg CB (2002) On the use of familial aggregation in population-based case probands for calculating penetrance. J Natl Cancer Inst 94: $1221-1226$

Brose MS, Rebbeck TR, Calzone KA, Stopfer JE, Nathanson KL, Weber BL, Isaacs C, Weber B, Moller P, Offit K, Kim-Sing C, Friedman E, Randall S, Pasini B, Ainsworth P, Gershoni-Baruch R, Foulkes WD, Klijn J, Tung N, Rennert G, Olopade O, Couch F, Wagner T, Olsson H, Sun P, Weitzel JN, Narod SA (2002) Cancer risk estimates for BRCA1 mutation carriers identified in a risk evaluation program. J Natl Cancer Inst 94: 1365-1372

Cullinane CA, Lubinski J, Neuhausen SL, Ghadirian P, Lynch HT (2005) Effect of pregnancy as a risk factor for breast cancer in BRCA1/BRCA2 mutation carriers. Int J Cancer 117: 988-991

Dumitrescu RG, Cotarla I (2005) Understanding breast cancer risk - where do we stand in 2005? J Cell Mol Med 9: 208-221

Easton DF, Ford D, Bishop DT (1995) Breast and ovarian cancer incidence in BRCA1-mutation carriers. Breast Cancer Linkage Consortium. Am J Hum Genet 56: 265-271

Ford D, Easton DF, Stratton M, Narod S, Goldgar D, Devilee P, Bishop DT, Weber B, Lenoir G, Chang-Claude J, Sobol H, Teare MD, Struewing J, Arason A, Scherneck S, Peto J, Rebbeck TR, Tonin P, Neuhausen S, Barkardottir R, Eyfjord J, Lynch H, Ponder BA, Gayther SA, ZeladaHedman M, the Breast Cancer Linkage Consortium (1998) Genetic heterogeneity and penetrance analysis of the BRCA1 and BRCA2 genes in breast cancer families. The Breast Cancer Linkage Consortium. Am J Hum Genet 62: 676-689

Gruber SB, Petersen GM (2002) Cancer risks in BRCA1 carriers: time for the next generation of studies. J Natl Cancer Inst 94: 1344-1345

Hearle N, Damato BE, Humphreys J, Wixey J, Green H, Stone J, Easton DF, Houlston RS (2003) Contribution of germline mutations in BRCA2, P16(INK4A), P14(ARF) and P15 to uveal melanoma. Invest Ophthalmol Vis Sci 44: 458-462

Jernstrom H, Loman N, Johannsson OT, Borg A, Olsson H (2005) Impact of teenage oral contraceptive use in a population-based series of early-onset breast cancer cases who have undergone BRCA mutation testing. Eur J Cancer 41: 2312-2320

Jernstrom H, Lubinski J, Lynch HT, Ghadirian P, Neuhausen S, Isaacs C, Weber BL, Horsman D, Rosen B, Foulkes WD, Friedman E, GershoniBaruch R, Ainsworth P, Daly M, Garber J, Olsson H, Sun P, Narod SA (2004) Breast-feeding and the risk of breast cancer in BRCA1 and BRCA2 mutation carriers. J Natl Cancer Inst 96: 1094-1098

King MC, Marks JH, Mandell JB (2003) Breast and ovarian cancer risks due to inherited mutations in BRCA1 and BRCA2. Science 302: 643-646, doi: $10.1126 /$ science.1088759

Kotsopoulos J, Lubinski J, Lynch HT, Neuhausen SL, Ghadirian P, Isaacs C, Weber B, Kim-Sing C, Foulkes WD, Gershoni-Baruch R, Ainsworth P, Friedman E, Daly M, Garber JE, Karlan B, Olopade OI, Tung N, Saal HM, Eisen A, Osborne M, Olsson H, Gilchrist D, Sun P, Narod SA (2005) Age at menarche and the risk of breast cancer in BRCA1 and BRCA2 mutation carriers. Cancer Causes Control 16: $667-674$ 
Liede A, Karlan BY, Narod SA (2004) Cancer risks for male carriers of germline mutations in BRCA1 or BRCA2: a review of the literature. J Clin Oncol 22: 735 - 742, doi: 10.1200/JCO.2004.05.055

Milne RL, Knight JA, John EM, Dite GS, Balbuena R, Ziogas A, Andrulis IL, West DW, Li FP, Southey MC, Giles GG, McCredie MR, Hopper JL, Whittemore AS (2005) Oral contraceptive use and risk of early-onset breast cancer in carriers and noncarriers of BRCA1 and BRCA2 mutations. Cancer Epidemiol Biomarkers Prev 14: 350-356

Narod SA (2002a) Modifiers of risk of hereditary breast and ovarian cancer. Nat Rev Cancer 2: $113-123$

Narod SA, Dube MP, Klijn J, Lubinski J, Lynch HT, Ghadirian P, Provencher D, Heimdal K, Moller P, Robson M, Offit K, Isaacs C, Weber B, Friedman E, Gershoni-Baruch R, Rennert G, Pasini B, Wagner T, Daly M, Garber JE, Neuhausen SL, Ainsworth P, Olsson H, Evans G, Osborne M, Couch F, Foulkes WD, Warner E, Kim-Sing C, Olopade O, Tung N, Saal HM, Weitzel J, Merajver S, Gauthier-Villars M, Jernstrom H, Sun P, Brunet JS (2002b) Oral contraceptives and the risk of breast cancer in BRCA1 and BRCA2 mutation carriers. J Natl Cancer Inst 94: 1773-1779

Narod SA, Lubinski J, Ghadirian P, Lynch HT, Moller P, Foulkes WD, Rosen B, Kim-Sing C, Isaacs C, Domchek S, Sun P (2006) Screening mammography and risk of breast cancer in BRCA1 and BRCA2 mutation carriers: a case-control study. Lancet Oncol 7: 402-406

Niell BL, Rennert G, Bonner JD, Almog R, Tomsho LP, Gruber SB (2004) BRCA1 and BRCA2 founder mutations and the risk of colorectal cancer. J Natl Cancer Inst 96: 15-21, doi: 10.1093/jnci/djh008

Nkondjock A, Robidoux A, Paredes Y, Narod SA, Ghadirian P (2006b) Diet, lifestyle and BRCA-related breast cancer risk among French-Canadians. Breast Cancer Res Treat 98: 285-294

Simchoni S, Friedman E, Kaufman B, Gershoni-Baruch R, Orr-Urtreger A, Kedar-Barnes I, Shiri-Sverdlov R, Dagan E, Tsabari S, Shohat M, Catane R, King MC, Lahad A, Levy-Lahad E (2006) Familial clustering of sitespecific cancer risks associated with BRCA1 and BRCA2 mutations in the Ashkenazi Jewish population. Proc Natl Acad Sci USA 103: 3770 - 3774

Spurdle AB, Antoniou AC, Duffy DL, Pandeya N, Kelemen L, Chen X, Peock S, Cook MR, Smith PL, Purdie M, Newman B, Dite GS, Apicella C, Southey MC, Giles GG, Hopper JL, Chenevix-Trench G, Easton DF,
EMBRACE Study Collaborators (2005) The androgen receptor CAG repeat polymorphism and modification of breast cancer risk in BRCA1 and BRCA2 mutation carriers. Breast Cancer Res 7: R176-R183

Spurdle AB, Antoniou AC, Kelemen L, Holland H, Peock S, Cook MR, Smith PL, Greene MH, Simard J, Plourde M, Southey MC, Godwin AK, Beck J, Miron A, Daly MB, Santella RM, Hopper JL, John EM, Andrulis IL, Durocher F, Struewing JP, Easton DF, Chenevix-Trench G, Australian Breast Cancer Family Study, Australian Jewish Breast Cancer Study, Breast Cancer Family Registry, Interdisciplinary Health Research International Team on Breast Cancer Susceptibility, The Kathleen Cunningham Foundation Consortium for Research into Familial Breast Cancer, Epidemiological Study of Familial Breast Cancer Study Collaborators (2006) The AIB1 polyglutamine repeat does not modify breast cancer risk in BRCA1 and BRCA2 mutation carriers. Cancer Epidemiol Biomarkers Prev 15: $76-79$

Struewing JP, Hartge P, Wacholder S, Baker SM, Berlin M, McAdams M, Timmerman MM, Brody LC, Tucker MA (1997) The risk of cancer associated with specific mutations of BRCA1 and BRCA2 among Ashkenazi Jews. N Engl J Med 336: $1401-1408$

The Breast Cancer Linkage Consortium (1999) Cancer risks in BRCA2 mutation carriers. J Natl Cancer Inst 91: 1310-1316

Thompson D, Easton D (2001) Variation in cancer risks, by mutation position, in BRCA2 mutation carriers. Am J Hum Genet 68: 410-419

Thompson D, Easton DF (2002) Cancer incidence in BRCA1 mutation carriers. J Natl Cancer Inst 94: 1358-1365

van Asperen CJ, Brohet RM, Meijers-Heijboer EJ, Hoogerbrugge N, Verhoef S, Vasen HF, Ausems MG, Menko FH, Gomez Garcia EB, Klijn JG, Hogervorst FB, van Houwelingen JC, van't Veer LJ, Rookus MA, van Leeuwen FE (2005) Cancer risks in BRCA2 families: estimates for sites other than breast and ovary. J Med Genet 42: 711-719, doi: 10.1136/ jmg.2004.028829

Whittemore AS, Balise RR, Pharoah PD, Dicioccio RA, Oakley-Girvan I, Ramus SJ, Daly M, Usinowicz MB, Garlinghouse-Jones K, Ponder BA, Buys S, Senie R, Andrulis I, John E, Hopper JL, Piver MS (2004) Oral contraceptive use and ovarian cancer risk among carriers of BRCA1 or BRCA2 mutations. Br J Cancer 91: $1911-1915$ 